Thorax (1965), 20, 175 .

\title{
Regional lung function in kyphoscoliosis
}

\author{
C. T. DOLLERY, P. M. S. G ILLAM, P. HUGH-J ONES, A D \\ P. A. ZOR A B
}

\begin{abstract}
From the Departments of Medicine, Postgraduate Medical School, Hammersmith Hospital, and the Brompton Hospital, London
\end{abstract}

Young patients with idiopathic kyphoscoliosis are often symptom-free and remain so until middle age, when those with severe deformity may become breathless on exertion and develop respiratory or, less often, cardiac failure. Kyphoscoliosis is, by definition, primarily a disorder of the spine, but the consequent rotation of the thorax and the distortion of the trunk may be severe, especially if much lateral curvature is present. The result is to diminish the intrathoracic volume and distort its contents (Chapman, Dill. and Graybiel, 1939). Patients with kyphoscoliosis who are short of breath usually have rapid, shallow breathing which expends most of the tidal volume in the dead space and leaves some alveoli underventilated. The work and energy cost of breathing is high in the older patients because of the abnormally high elastic resistance of the chest wall (Bergofsky, Turino, and Fishman, 1959), although children with kyphoscoliosis do not usually have a rigid thorax (Caro and DuBois, 1961).

As the excursion of the distorted thoracic cage is limited in patients with severe deformity, it is possible that regions of hypoventilation may arise, especially on the side of the scoliotic concavity. Radioactive gas methods provide a convenient opportunity to explore regional lung function, and

1 This work was supported by the Medical Research Council a group of 10 patients with severe kyphoscoliosis have been studied using radioactive xenon-133.

\section{THE PATIENTS}

Ten patients were studied, two of them before and after costectomy. The majority were referred to Brompton Hospital from the Scoliosis Clinic of the Royal National Orthopaedic Hospital by Mr. C. W. Manning. All but three were young, and only these three, who also had bronchitis, had effort dyspnoea. However, their ability to exercise was often restricted by the muscular wasting which had followed previous poliomyelitis. None had any cardiac disorder. Details of the patients' age, diagnosis, and severity of kyphoscoliosis are given in Table I. Many had severe deformity and had received or now needed surgical treatment. The severity of the scoliosis was graded radiographically from the angle the spine made at the point of greatest lateral curvature. An angle of $0^{\circ}$ to $30^{\circ}$ was graded $1,30^{\circ}$ to $60^{\circ}$ as grade 2 , $60^{\circ}$ to $90^{\circ}$ as grade 3, and greater than $90^{\circ}$ as grade 4 .

\section{METHODS}

APPARATUS Pairs of crystal scintillation counters were used with $1 \frac{1}{2}$ in. $(3.8 \mathrm{~cm}$.) diameter $\times 1$ in.

T A B LE I

AETIOLOGY AND SEVERITY OF KYPHOSCOLIOSIS

\begin{tabular}{|c|c|c|c|c|c|c|c|c|}
\hline Patient & Age (yr.) & Sex & Diagnosis & Grade & $\begin{array}{l}\text { Side of } \\
\text { Hump }\end{array}$ & Bronchitis & $\begin{array}{l}\text { F.E.V. }{ }^{\prime} \\
\text { F.V.C. }(\%)\end{array}$ & Other Information \\
\hline $\begin{array}{l}\text { M. W. } \\
\text { I. A. } \\
\text { J. A. } \\
\text { L. C. } \\
\text { J. D. } \\
\text { C. L. } \\
\text { E. L. } \\
\text { D. M. } \\
\text { P. S. } \\
\text { E. M. }\end{array}$ & $\begin{array}{l}17 \\
18 \\
16 \\
41 \\
19 \\
17 \\
15 \\
43 \\
22 \\
34\end{array}$ & $\begin{array}{l}\mathbf{F} \\
\mathbf{F} \\
\mathbf{F} \\
\mathbf{F} \\
\mathbf{F} \\
\mathbf{F} \\
\mathbf{F} \\
\mathbf{F} \\
\mathbf{F} \\
\mathbf{M}\end{array}$ & $\begin{array}{l}\text { Idiopathic } \\
\text { Paralytic } \\
\text { Idiopathic } \\
\text { Idiopathic } \\
\text { Idiopathic } \\
\text { Paralytic } \\
\text { Paralytic } \\
\text { Idiopathic } \\
\text { Paralytic } \\
\text { Idiopathic }\end{array}$ & $\begin{array}{l}\text { III } \\
\text { III } \\
\text { III } \\
\text { II } \\
\text { II } \\
\text { III } \\
\text { III } \\
\text { III } \\
\text { IV } \\
\text { I }\end{array}$ & $\begin{array}{l}\mathbf{R} \\
\mathbf{R} \\
\mathbf{L} \\
\mathbf{L} \\
\mathbf{R} \\
\mathbf{R} \\
\mathbf{R} \\
\mathbf{R} \\
\mathbf{R} \\
\mathbf{R}\end{array}$ & $\begin{array}{l}\text { No } \\
\text { No } \\
\text { No } \\
\text { Yes } \\
\text { No } \\
\text { No } \\
\text { No } \\
\text { Yes } \\
\text { No } \\
\text { Yes }\end{array}$ & $\begin{array}{l}- \\
87 \\
54 \\
82 \cdot 5 \\
82 \\
87 \cdot 5 \\
79 \\
-\end{array}$ & $\begin{array}{l}\text { Costectomy Oct. } 1962 \\
\text { Spinal fusion } 1956 \\
\text { Spinal fusion } 1959 \\
\text { Breathless on moderate effort. } \\
\text { Spinal fusion } 1955 \text {. Costectomy Sept. } 1963 \\
\text { Spinal fusion } 1960 \text {. Paralysed left diaphragm } \\
\text { Spinal fusion } 1960 \\
\text { Breathless on moderate effort } \\
\text { Spinal fusion } 1955 \text {. Left diaphragm very } \\
\text { weak } \\
\text { Heavy smoker with chronic cough }\end{array}$ \\
\hline
\end{tabular}


$(2.5 \mathrm{~cm}$.) thick sodium iodide crystals and conical lead collimators 6 in. $\left(15 \cdot 2 \mathrm{~cm}\right.$.) long with $1 \frac{1}{2}$ in. $\left(3.8 \mathrm{~cm}\right.$.) aperture at the crystal and $\frac{1}{2}$ in. $(1 \cdot 27 \mathrm{~cm}$.) aperture at the external orifice. The signals from the crystals were amplified, fed to rate meters, and displayed on pen recorders (Dollery, Hugh-Jones, and Matthews, 1962). ${ }^{133}$ Xenon was administered intravenously as a 0.5 to 1.0 millicurie dose dissolved in saline, and taken as a slow deep breath followed by two-minute rebreathing from a spirometer containing 0.6 to 1.0 millicurie of ${ }^{133} \mathrm{Xe}$ per litre. The radiation dose from this procedure is about 70 millirads.

STATIONARY COUNTERS Seven patients were studied using two pairs of stationary counters which were repositioned over four or six separate areas on different breaths. Usually the positions chosen were the level of the sternal angle and 5 and $10 \mathrm{~cm}$. below this level. The distribution of ventilation was measured from the radioactivity entering each area after a slow deep breath, and perfusion from the amount evolved into the lungs in each area after an intravenous injection of ${ }^{13} \mathrm{Xe}$ dissolved in saline. The relative alveolar volume in each area was determined by rebreathing ${ }^{13.3} \mathrm{Xe}$ on a closed circuit for two minutes to produce even labelling of the alveolar gas (Ball, Stewart, Newsham, and Bates, 1962). The rate of wash-out of ${ }^{133} \mathrm{Xe}$ from each area was also determined as a further measure of regional ventilation (Dollery et al., 1962). Care was taken to make the lung volume calibrations at approximately the same inspired volume as the 'ventilation' and 'perfusion' measurements.

SCANNING WITH MOVING COUNTERS Six patients (including three of those studied with stationary counters) were investigated using motor-driven counters which moved vertically over the lungs from base to apex during breath holding. This method of scanning the lung provides a complete plot of the distribution of radioactivity in the vertical plane instead of only in the isolated areas seen with the stationary counters (Dollery and Gillam, 1963).

CALCulations The purpose of these methods, using ${ }^{133} \mathrm{Xe}$, is to compare the amount of radioactivity in two or more areas after a slow deep breath (ventilation), an intravenous injection (perfusion), and rebreathing to equilibrate the isotope throughout the alveolar gas (volume). The ratios of counting rates after the three different manœuvres are used to compare the ratios of ventilation/perfusion, ventilation/ volume, and perfusion/volume in different regions. As slightly different amounts of radioactivity are used in different individuals, the figures must be scaled to allow comparisons. This is done by summing the counting rates in all the areas after each of the three manœuvres and scaling them to a common figure so that the overall ratios of ventilation/perfusion, etc., are unity. For the stationary counters the counting rates in the four or six separate areas are summed and, for scanning, the counting rates every half inch

up the lung (equivalent to about 22 separate positions). As the counters do not have a uniform sensitivity throughout their counting field this method of comparison is only an approximation. After scaling the sum of the counting rates the individual ratios are calculated, and, to compare the results of the whole group, values at the level of the second rib and $10 \mathrm{~cm}$. lower have been used (Table II). Although the overall ratios of ventilation/volume and perfusion/volume are unity the average ratio in these four regions is not necessarily unity unless distribution is completely even.

This method of comparison is invalid if there are very badly ventilated areas which do not become uniformly labelled with isotope during the two-minute rebreathing period. In these instances the wash-out rates are used to compare ventilation because the volume measurement after two minutes' rebreathing is too low. It is impossible to allow for this error in the perfusion/volume ratios, so that this ratio tends to be too high in poorly ventilated areas.

\section{RESULTS}

The main features of the results are summarized in Table II. The ventilation and perfusion per unit of lung volume at the level of the second rib and $10 \mathrm{~cm}$. lower down over each lung are used for comparison with normal subjects. The ratio of blood flow per unit of lung volume at the level of the second rib compared with that at the level of the fifth interspace (approximately $10 \mathrm{~cm}$. lower) is about $0 \cdot 22$ in upright normal

\section{T A B L E I I}

COMPARISON OF BLOOD FLOW AND VENTILATION AT THE LEVEL OF THE SECOND RIB AND $10 \mathrm{~cm}$. LOWER

\begin{tabular}{|c|c|c|c|c|c|}
\hline \multirow{2}{*}{ Patient } & \multirow{2}{*}{ Zone } & \multicolumn{2}{|c|}{ Blood Flow Volume } & \multicolumn{2}{|c|}{ Ventilation/Volume } \\
\hline & & Left & Right & Left & Right \\
\hline M. W. & $\begin{array}{l}\text { Upper } \\
\text { Lower }\end{array}$ & $\begin{array}{l}0.8 \\
0.9\end{array}$ & $\begin{array}{l}1 \cdot 3 \\
1 \cdot 1\end{array}$ & $\begin{array}{l}1 \cdot 2 \\
0.6\end{array}$ & $\begin{array}{l}1.6 \\
0.6\end{array}$ \\
\hline i. A. & $\begin{array}{l}\text { Upper } \\
\text { Lower }\end{array}$ & $\begin{array}{l}1 \cdot 0 \\
1.1\end{array}$ & $\begin{array}{l}0.9 \\
1.1\end{array}$ & $\begin{array}{l}1 \cdot 1 \\
1 \cdot 1\end{array}$ & $\begin{array}{l}0 \cdot 9 \\
1 \cdot 1\end{array}$ \\
\hline J. A. & $\begin{array}{l}\text { Upper } \\
\text { Lower }\end{array}$ & $\begin{array}{l}0.6 \\
1.3\end{array}$ & $\begin{array}{l}0 \cdot 8 \\
1 \cdot 3\end{array}$ & $\begin{array}{l}0.7 \\
1.0\end{array}$ & $\begin{array}{l}0 \cdot 8 \\
1 \cdot 1\end{array}$ \\
\hline L. C. & $\begin{array}{l}\text { Upper } \\
\text { Lower }\end{array}$ & $\begin{array}{l}1 \cdot 3 \\
1 \cdot 0\end{array}$ & $\begin{array}{l}1 \cdot 8 \\
0 \cdot 7\end{array}$ & $\begin{array}{l}1.5 \\
0.5\end{array}$ & $\begin{array}{l}1 \cdot 2 \\
0 \cdot 8\end{array}$ \\
\hline J. D. & $\begin{array}{l}\text { Upper } \\
\text { Lower }\end{array}$ & $\begin{array}{l}1 \cdot 6 \\
1 \cdot 1\end{array}$ & $\begin{array}{l}1.0 \\
0.6\end{array}$ & $\begin{array}{l}0.9 \\
1.0\end{array}$ & $\begin{array}{l}1 \cdot 0 \\
1 \cdot 2\end{array}$ \\
\hline C. L. & $\begin{array}{l}\text { Upper } \\
\text { Lower }\end{array}$ & $\begin{array}{l}0.9 \\
0.9\end{array}$ & $\begin{array}{l}1 \cdot 1 \\
1 \cdot 1\end{array}$ & $\begin{array}{l}1 \cdot 2 \\
0.4\end{array}$ & $\begin{array}{l}1.3 \\
0.9\end{array}$ \\
\hline E. L. & $\begin{array}{l}\text { Upper } \\
\text { Lower }\end{array}$ & $\begin{array}{l}1 \cdot 0 \\
1 \cdot 2 \\
\end{array}$ & $\begin{array}{l}0 \cdot 7 \\
1 \cdot 2 \\
\end{array}$ & $\begin{array}{l}0.9 \\
0.7\end{array}$ & $\begin{array}{l}0.9 \\
1.5\end{array}$ \\
\hline D. M. & $\begin{array}{l}\text { Upper } \\
\text { Lower }\end{array}$ & $\begin{array}{l}1 \cdot 0 \\
1.3\end{array}$ & $\begin{array}{l}0.6 \\
1.5\end{array}$ & $\begin{array}{l}1 \cdot 5 \\
0 \cdot 5\end{array}$ & $\begin{array}{l}1 \cdot 6 \\
0 \cdot 3\end{array}$ \\
\hline P. S. & $\begin{array}{l}\text { Upper } \\
\text { Lower }\end{array}$ & $\begin{array}{l}1.2 \\
0.6\end{array}$ & $\begin{array}{l}0 \cdot 8 \\
1 \cdot 4\end{array}$ & $\begin{array}{l}1 \cdot 1 \\
0 \cdot 9\end{array}$ & $\begin{array}{l}0.9 \\
1.1\end{array}$ \\
\hline E. M. & $\begin{array}{l}\text { Upper } \\
\text { Lower }\end{array}$ & $\begin{array}{l}0.9 \\
1.0\end{array}$ & $\begin{array}{l}1.6 \\
0.5\end{array}$ & $\begin{array}{l}1.6 \\
0.5\end{array}$ & $\begin{array}{l}1 \cdot 6 \\
0 \cdot 3\end{array}$ \\
\hline
\end{tabular}


subjects. For ventilation the same ratio is about 0.66 (West and Dollery, 1960).

DISTRIBUTION OF BLOOD FLOW The average ratio of blood flow at the level of the second rib to $10 \mathrm{~cm}$. lower was 0.95 . Thus the normal difference in flow between the upper and lower zones in the upright position was almost abolished (Fig. 1). In six patients, who were studied by scanning, a more complete picture of distribution is available. Two patterns were seen. Four patients had a fairly even distribution throughout both lungs (Fig. 3) and two had a peak of perfusion per unit volume in the mid-zones with a fall off towards both apex and base (Fig. 4).

A relatively even distribution of blood flow was not confined to the three patients who had abnormally poorly ventilated areas in the lower zones. In these patients a reduction in the blood flow to the lower zones might have resulted from local lung disease, but there was no other evidence of a lower zone abnormality in the seven other patients who showed less than the normal difference in blood flow at the two levels.

VENTILATION DISTRIBUTION Seven of the 10 patients had a fairly even distribution of ventilation throughout both lungs (Figs. 1 and 4) although there was some reduction in the ventilation of the lowermost parts of the lung in two of them. One patient (I.A.) has an even ventilation shown in Table II but the ventilation was reduced to the lowermost part of the lung more than 10 $\mathrm{cm}$. below the second rib (Fig. 3). The average ventilation per unit lung volume at the level of the second rib compared with that at a position $10 \mathrm{~cm}$. lower was $1 \cdot 46$. This value is high largely because three patients had very poorly ventilated areas at the lung bases. The wash-in and wash-out traces of one of these patients are shown in Fig. 2.

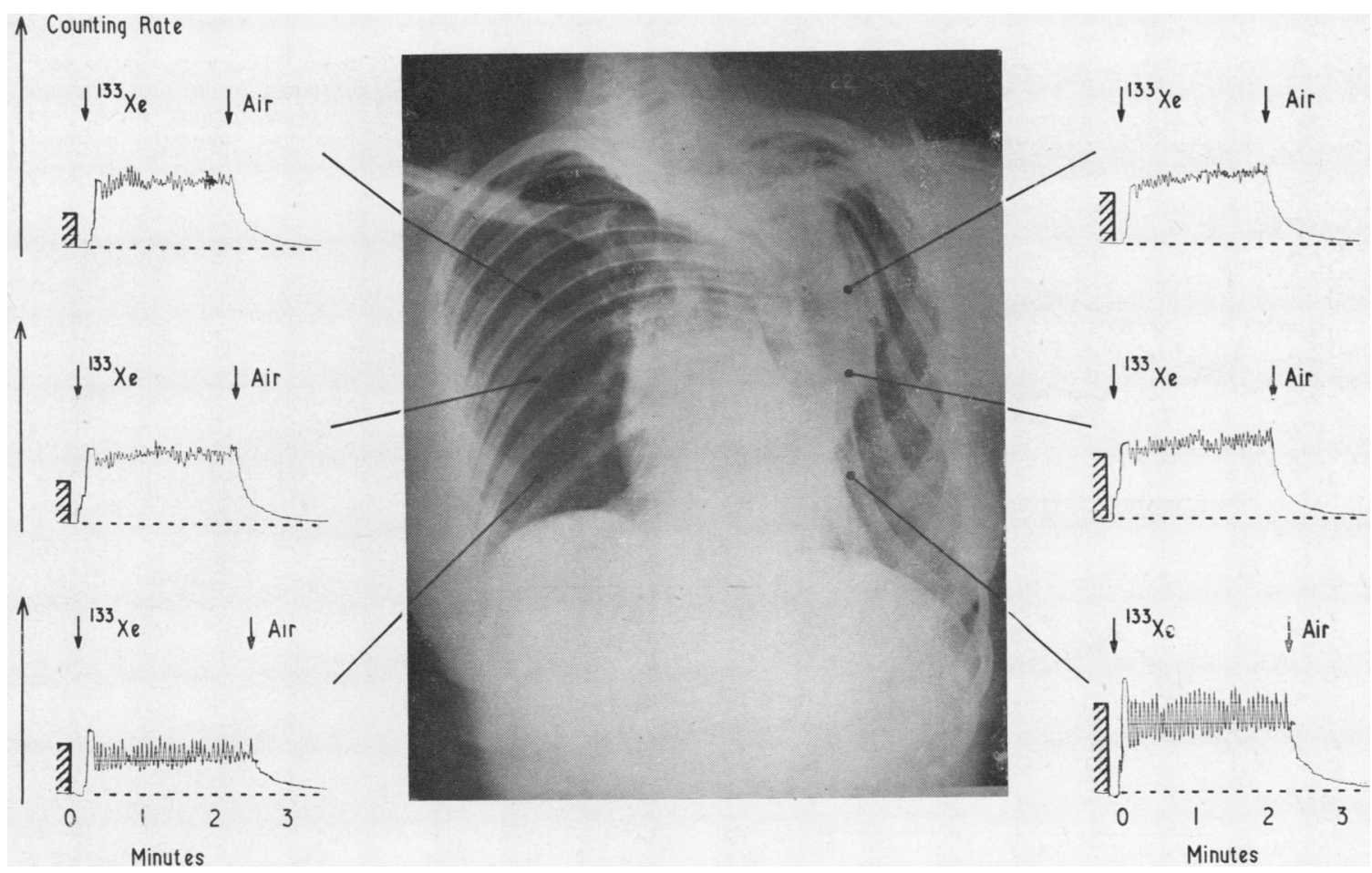

FIG. 1. J.A. Chest radiograph with ${ }^{13}$ 'Xe traces obtained from the upper, mid, and lower zones. The traces on the same horizontal level were recorded simultaneously. Counting rate is plotted vertically and time in minutes horizontally. The patient takes a normal tidal breath followed by a deep breath at the point marked '133Xe' and then rebreathes the isotope for about two and a half minutes. At the point marked 'air' the patient stops rebreathing and begins to wash out the isotope. The wash-in and wash-out times are normal in all six areas despite the severe deformity of the thoracic cage. The deflections obtained after injection of ${ }^{183}$ Xe dissolved in saline are shown as hatched columns. 


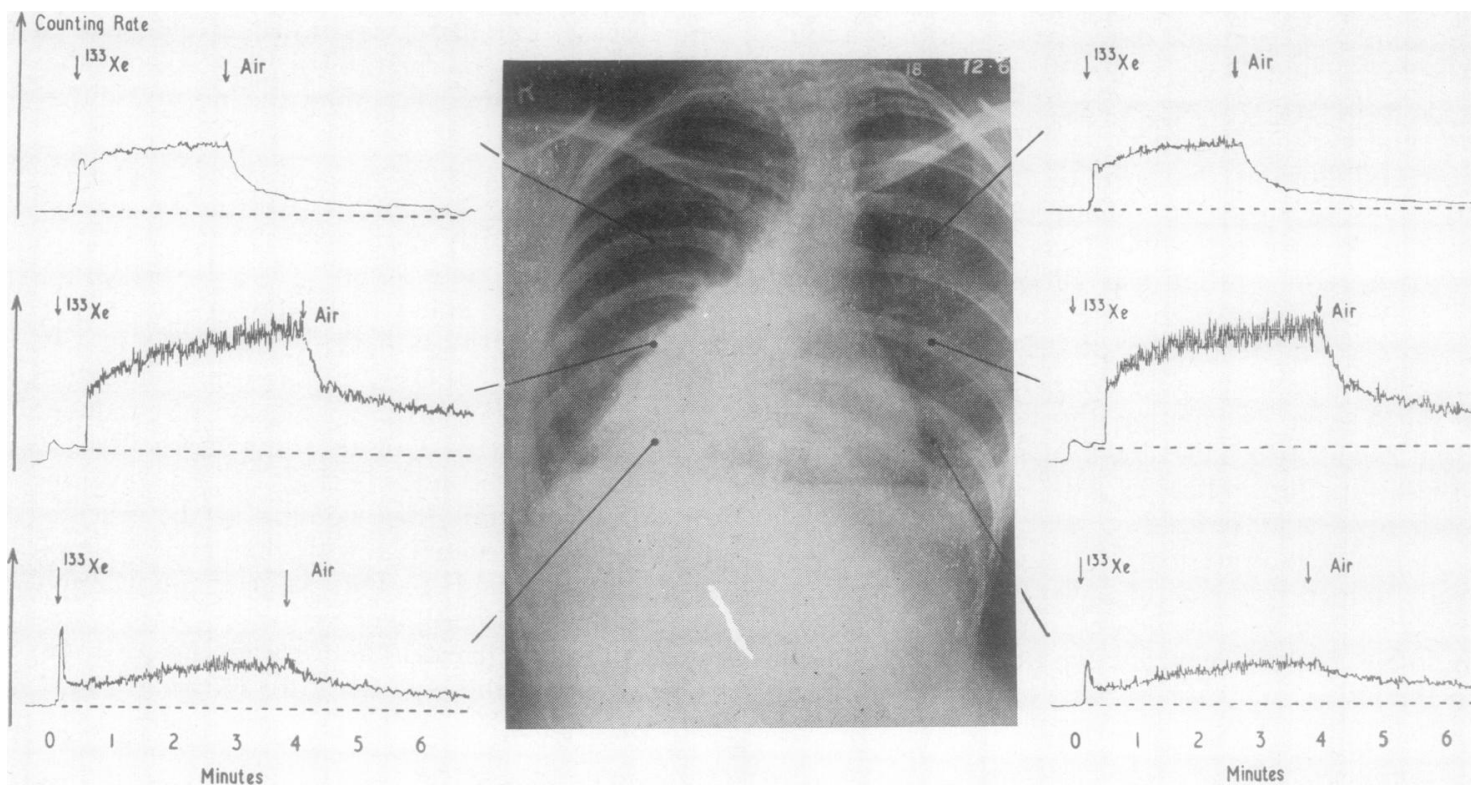

FIG. 2. D. M. Chest radiograph with ${ }^{133} X e$ wash-in and wash-out traces from six zones. The upper pair were recorded at $\frac{1}{3}$ sensitivity. The wash-in and wash-out from the lower zones are very slow (shown by a slow rise on ${ }^{133} \mathrm{Xe}$ and $a$ slow fall on air) although the radiograph shows no abnormality of the lung in those regions. In the mid zones, particularly the right, the wash-out is rapid at the beginning and then becomes very slow, suggesting a mixed population of alveoli with different ventilation characteristics.
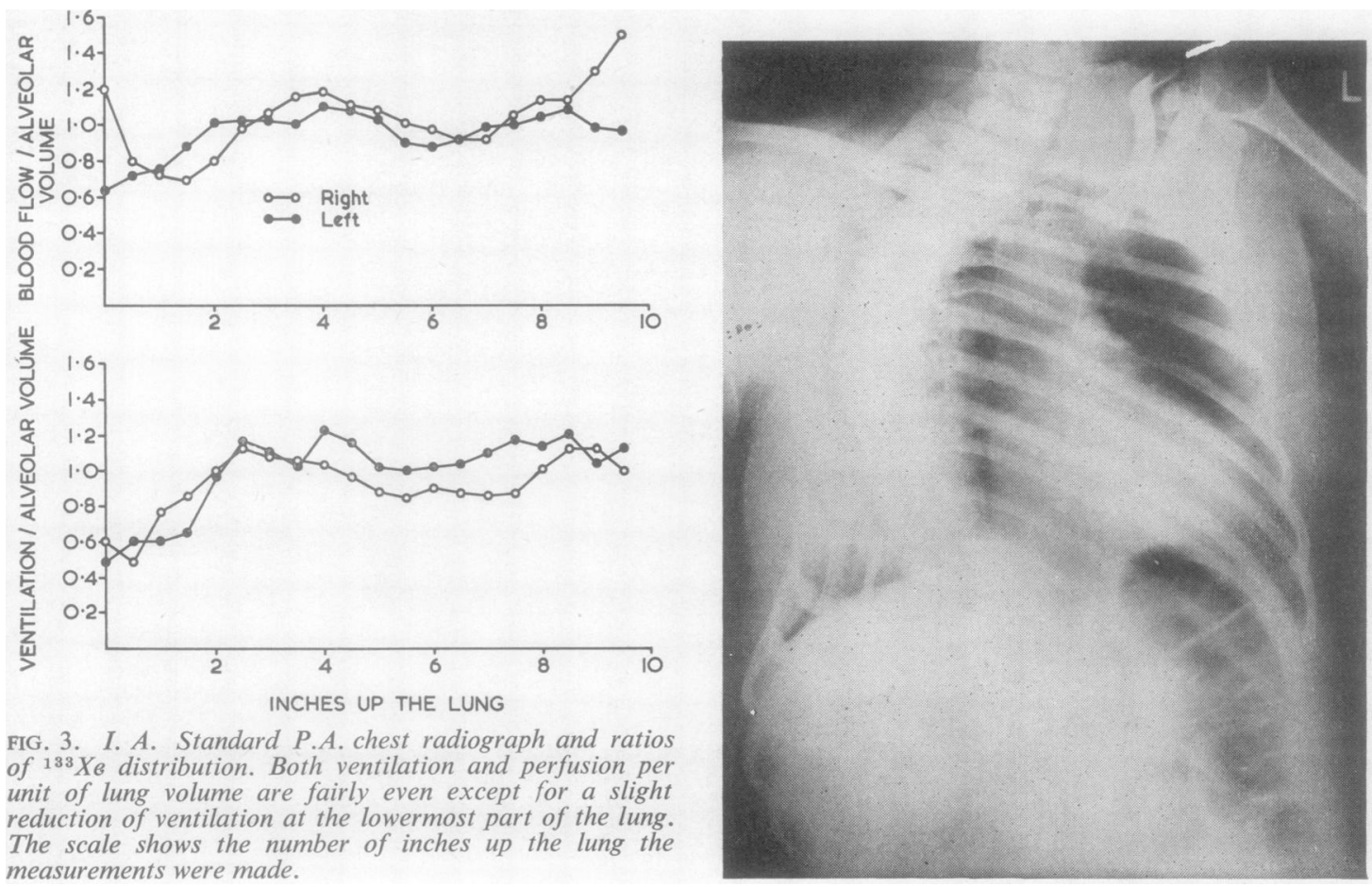

FIG. 3. I. A. Standard P.A. chest radiograph and ratios of ${ }^{133} \mathrm{Xe}$ distribution. Both ventilation and perfusion per unit of lung volume are fairly even except for a slight reduction of ventilation at the lowermost part of the lung. The scale shows the number of inches up the lung the measurements were made. 

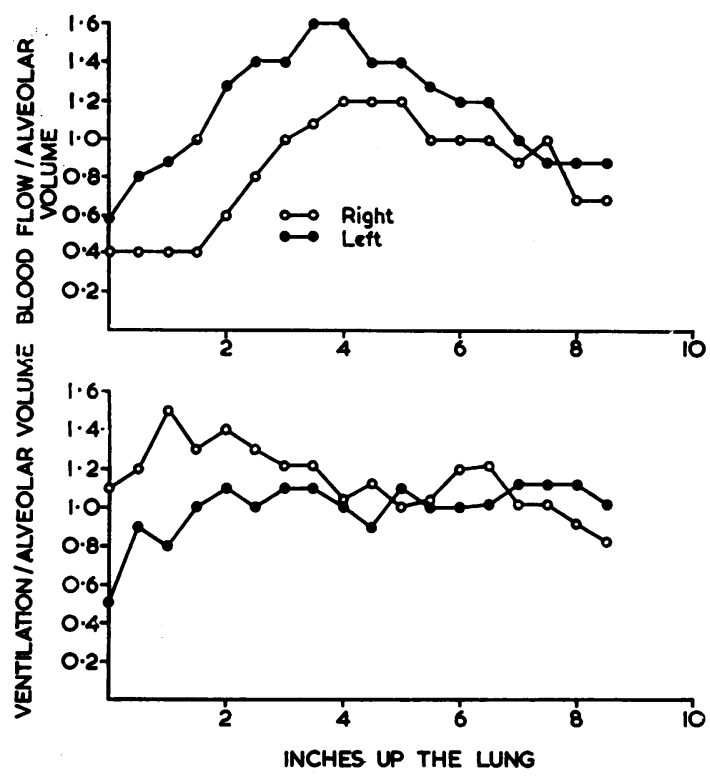

FIG. 4. M. W. Scans of ${ }^{133}$ Xe distribution, showing a fairly even distribution of ventilation but a distinct peak of blood flow in the mid zones. There is less flow per unit volume on the right side. The scale of inches shows the distance the counters have moved up the lung.

The severe reduction in the ventilation at the lung bases in three patients deserves comment. All three were older and had some symptoms suggesting chronic bronchitis, and one had only a moderate kyphoscoliosis. This patient (L. C.) had a ratio of F.E.V. $._{1} /$ F.V.C. of only $54 \%$, a finding compatible with moderate airways obstruction. The time of half wash-out of ${ }^{133} \mathrm{Xe}$ was 60 seconds (approximately twice normal) in the left lower zone although the radiograph appeared normal in that region. Another patient (E. M.) had a ratio of F.E.V. ${ }_{1}$ F.V.C. of only $55 \%$ with a half washout time of 160 seconds in the right lower zone and 100 seconds at the left lower zone, although the upper zone values were normal. The radiograph showed normal lungs. The third patient (D. M.) is described in more detail below. The two patients studied before and after costectomy did not have any significant change in regional function.

\section{CASE REPORTS}

Some of the features which were shown in this investigation are illustrated in the following short case reports.

PATIENT J. A. A girl aged 16 years. Idiopathic spinal curvature developed at the age of 7 years, and she was treated with a spinal support. Spinal fusion was performed in 1957, but a further fusion was necessary in 1959. Subsequently she was able to play games at school despite a grade 3 kyphoscoliosis. Her vital capacity is $2,500 \mathrm{ml}$. and the total lung capacity $4,510 \mathrm{ml}$.

The chest radiograph and xenon traces from three ievels in the lung are shown in Figure 1. The wash-in and wash-out of xenon are normal in all six areas studied. The ratio of blood flow to lung volume was lower in the upper zones than in the lower, but there was less than the normal difference between these zones.

PATIENT D. M. A woman aged 43 had a history of cough and sputum in the winter for several years. Idiopathic kyphoscoliosis had developed at the age of 14 years and progressed to grade 3 severity. She remained symptom-free until the age of 38 years. She is now breathless on moderately heavy exertion, such as climbing hills, and has bronchitis with occasional attacks of severe wheezing. The diaphragms move well on screening, and the E.C.G. is normal.

The chest radiograph and the xenon traces are shown in Figure 2. The scoliosis is in the lower thoracic spine with nearly $90^{\circ}$ of angulation. The ratio F.E.V.1/F.V.C. was $79 \%$. The xenon wash-out was extremely slow at both lower zones, having a half-time of 198 seconds on the concave aspect of the scoliosis (left) and 72 seconds on the convex aspect. The mid-zone traces showed a distinct change in slope of wash-out, suggesting that the alveoli consisted of widely separated populations with different ventilation characteristics.

PATIENT I. A. A girl aged 18 years. Scoliosis was first noticed at the age of 9 years. Spinal fusion was performed at the age of 11 years. This later became unstable and had to be repeated at the age of 13 years. The patient can now play all games at school and has no disability. There is a severe scoliosis (grade 3) with considerable rotation and a consequent 'hump' on the right posteriorly but no other abnormality.

The radiograph and scan of xenon distribution are shown in Figure 3. The distribution of blood flow per unit volume was fairly even throughout both lungs, although it is slightly higher in the mid and upper part of them than in the lowermost part. Ventilation per unit volume was even except for a slight reduction in the lowermost part of both lungs. The results were closely similar for both lungs with regard to both ventilation and perfusion distribution despite the severe chest deformity seen radiographically.

PATIEnT M. W. A girl aged 17 years. Scoliosis was first noticed at the age of 12 years. In addition to lateral spinal curvature, considerable rotation of the vertebral column was present, the ribs causing a 'hump' posteriorly on the right. She has no respiratory symptoms. Costectomy was performed to reduce the posterior prominence of the ribs. 
The results of the xenon scans are shown in Figure 4. The distribution of ventilation per unit volume was even throughout both lungs despite the grade 3 spinal deformity. Blood flow per unit volume had a distinct peak in the mid zones with a fall both above and below this level. Blood flow is lower on the right side than on the left, but the cause is not apparent.

\section{DISCUSSION}

The seven younger patients studied all had a fairly even distribution of ventilation, and the wash-out of xenon was not prolonged in any regions of the lung despite the gross deformity of the thorax. Radiographs of kyphoscoliotic patients are often more transradiant on the concave aspect of the kyphoscoliosis, and this may lead one to suppose that this is the more effective lung. The curvature of the spine reduces the antero-posterior diameter of the lung on the concave aspect, and consequently the lung volume on that side is reduced (cf., right lower zone in Fig. 1). The spine overlaps the opposite lung and obscures most of the lung from view even though there may be a greater volume on that side ( $c f$. , left lower zone in Fig. 1). In each, the ventilation proportional to volume is normal. Even ventilation is consistent with the finding of Iticovici and Lyons (1956) that intrapulmonary gas mixing is rapid, and the observation of Bergofsky et al. (1959) that the wash-out of nitrogen during oxygen breathing is usually normal in patients with kyphoscoliosis. Bedell. Marshall, DuBois, and Comroe (1956) used the body plethysmograph to detect gas trapped in very poorly ventilated spaces in the lung and found that there was little evidence of such trapping in four patients with kyphoscoliosis. Thus the poor ventilation of the lower lung zones of the three older patients is difficult to evaluate. Two of these patients had moderately severe airway obstruction, and this is an uncommon finding in patients with kyphoscoliosis, though airway resistance may be increased (Cotrel, Prime, and Zorab, 1964). All three had mild chronic bronchitis, and poorly ventilated regions of lung are sometimes found in bronchitic patients despite normal radiographic appearances (Dollery et al., 1962). Areas of atelectasis, sometimes involving a whole lobe or lung, have been described in patients with kyphoscoliosis, and small areas of emphysema have sometimes been noted (Fischer and Dolehide, 1954 ; Bergofsky et al., 1959). An area of atelectasis is unlikely to have been responsible for the slow wash-out of xenon. Emphysema, or airway obstruction, caused by the chronic bronchitis was probably responsible.
Almost even perfusion of the lungs was observed in all 10 patients. This was an unexpected finding as it suggests that there was an abnormality in the pulmonary circulation even in those patients who were entirely symptom-free. The preferential distribution of blood flow to the dependent parts of the normal lung can be explained by the mechanical characteristics of the pulmonary blood vessels and the height of the pulmonary arterial, venous, and alveolar pressures (West, Dollery, and Naimark, 1964). The pulmonary artery pressure at the top of the upright normal lung only just reaches the level of the alveolar pressure because of the hydrostatic pressure of the column of blood from the hilum to the apex of the lung. As a result flow is almost zero at this level. Patients with severe kyphoscoliosis have a foreshortened thorax, so that the vertical height of the lung tissue may be greatly reduced. Some of our patients' lungs measured only $20 \mathrm{~cm}$. vertically on chest radiographs. Bergofsky et al. (1959) illustrate whole lung sections prepared by Gough and Thomas, one of which is $14 \mathrm{~cm}$. and the other $19 \mathrm{~cm}$. high. These authors studied several patients by cardiac catheterization and found an average pulmonary arterial pressure of $17 / 11 \mathrm{~mm}$. in asymptomatic patients and $25 / 14 \mathrm{~mm}$. $\mathrm{Hg}$ in those with exertional dyspnoea. Hanley, Platts, Clifton, and Morris (1958) catheterized the heart of three patients with kyphoscoliosis, one of whom had never been in heart failure. This patient had a pulmonary arterial pressure of $45 / 25 \mathrm{~mm}$. A foreshortened lung. even with normal pulmonary pressures, will have less than the normal difference in flow between its upper and lower parts. If the pulmonary artery pressure is increased, the difference between upper and lower zones will be reduced further.

An additional factor is the height of the pulmonary venous pressure. Bergofsky et al. (1959) observed a pulmonary wedge pressure of $7 \mathrm{~mm}$. $\mathrm{Hg}(10 \mathrm{~cm}$. blood) in two asymptomatic patients with kyphoscoliosis. The vertical height of the lung may be so much reduced that a pulmonary venous pressure at this level would be above the top of the lung. In this situation the arterio-venous pressure difference is constant throughout the lung, and differences in resistance at different levels depend only upon changes in the hydrostatic distending pressure. The proportional difference in the distending pressure at the two levels will be reduced if the pulmonary artery and venous pressures are raised (West et al., 1964). However, this may not be the whole explanation, and some other factor such as a change in the 
distensibility of the pulmonary blood vessels may also be important.

Some authors have suggested that distortion of the heart and great vessels by kyphoscoliosis may lead to an obstruction of blood flow, particularly by kinking the aorta (Coombs, 1930). Careful dissection at three necropsies recorded by Bergofsky et al. (1959) did not reveal any evidence of kinking of vessels. Furthermore, Zorab (1964) found cardiac murmurs to be very uncommon in 150 cases of scoliosis except when heart disease was present. This factor can therefore be discounted as an important influence on intrapulmonary flow distribution.

Even perfusion has one important physiological consequence. As flow increases through the normal lung the pulmonary vascular resistance falls because a rise in pulmonary arterial pressure recruits more capillaries in the under-perfused upper parts of the lung. When perfusion is even at rest this mechanism is absent. The increase in blood flow on exercise will cause a much sharper rise in pulmonary arterial pressure. This factor may add to the load on the right ventricle caused by chronic hypoventilation and increase the tendency to heart failure.

\section{SUMMARY}

Regional lung function has been studied in 10 patients with severe kyphoscoliosis using ${ }^{133} \mathrm{Xe}$.

Seven of the patients were less than 23 years old and were free of respiratory symptoms. They all had fairly even ventilation and perfusion of both lungs, although two had slight reduction of the ventilation in the lowermost part of the lung and two others had a moderate mid-zone peak of perfusion. Even perfusion of the lung is abnormal in the upright position, but it can be explained in part by the reduced vertical height of the lung and an increase in pulmonary vascular pressures.
Three of the patients were between 34 and 43 years old, and these all had mild chronic bronchitis with dyspnoea on moderate effort. All three showed reduction of ventilation in the lower zones, and in two this was of severe degree. The chest radiographs did not reveal any explanation for the poor ventilation, and the relationship of this to kyphoscoliosis, if any, is unexplained.

We thank Mr. C. W. Manning and Dr. F. H. Scadding for referring patients and for helpful advice. We are grateful to Mr. G. Forse for skilled technical assistance and to the M.R.C. Cyclotron Unit for the use of their facilities. We are also grateful to the Sir Halley Stewart Trust and the Poliomyelitis Research Fund for grants supporting this work.

\section{REFERENCES}

Ball, W. C., Stewàrt, P. B., Newsham, L. G. S., and Bates, D. V. (1962). Regional pulmonary function studied with xenon 133. J. clin. Invest., 41, 519.

Bedell, G. N., Marshall, R., DuBois, A. B., and Comroe, J. H. (1956) Plethysmographic determination of the volume of gas trapped in the lungs. Ibid., 35, 664.

Bergofsky, E. H., Turino, G. M., and Fishman, A. P. (1959). Cardiorespiratory failure in kyphoscoliosis. Medicine (Baltimore), 38, 263.

Caro, C. G., and DuBois, A. B. (1961). Pulmonary function in kyphoscoliosis. Thorax, 16, 282.

Chapman, E. M., Dill, D. B., and Graybiel, A. (1939). The decrease in functional capacity of the lungs and heart resulting from deformities of the chest : pulmonocardiac failure. Medicine (Baltimore), 18, 167 .

Cotrel, Y., Prime, F. J., and Zorab, P. A. (1964). Airway resistance in kyphosculiosis (unpublished)

Dollery, C. T., Hugh-Jones, P., and Matthews, C. M. E. (1962) Use of radioactive xenon for studies of regional lung function. Brit. med. J., 2, 1006 .

_ and Gillam, P. M. S. (1963). The distribution of blood and gas within the lungs measured by scanning after administration of ${ }_{133} \mathrm{Xe}$. Thorax, 18, 316 .

Fischer, J. W., and Dolehide, R. A. (1954). Fatal cardiac failure persons with thoracic deformities. Arch.intern. Med., 93, 687. in

Hanley, T., Platts, M. M., Clifton, M., and Morris, T. L. (1958). Heart failure of the hunchback. Quart. J. Med., $27,155$.

Iticovici, H. N., and Lyons, H. A. (1956). Ventilatory and lung volume determinations in patients with chest deformities. Amer. J. med. Sci., 232, 265.

West J. B and Dollery, C. T. (1960). Distribution of blood flow and ventilation-perfusion ratio in the lung, measured with radioventilation-perfusion ratio in the lun
active $\mathrm{CO}_{2}$. J. appl. Physiol., 15, 405. active $\mathrm{CO}_{2}$. J. appl. Physiol., 15 , 405 . isolated lung; relation to vascular and alveolar pressures. Ibid., in press.

Zorab, P. A. (1964). Unpublished observations. 